\title{
Research on Application of Building Energy-saving Strategy in Building Design
}

\author{
ZHANG Xuchen \\ Southwest Jiao Tong University School of Architecture, China \\ email: zhangxuchen457@126.com
}

\begin{abstract}
Energy has become an important link in current sustainable development strategy. Construction of energy-saving building has become important development direction of urban construction in the future. Therefore discussion of building energy conservation has important significance on urban development and construction. In the paper, two basic approaches of building energy conservation are discussed, namely consumption restriction and source expansion. In addition, application of building energy-saving strategy in building design is mainly described, mainly including three major aspects, energy-saving design of building surrounding protection system, energy-saving design of surrounding environment system and energy-saving design of building body. It has certain positive significance on in-depth development of saving energy for buildings.
\end{abstract}

Keywords: building energy-saving; building design; surrounding protection system; building body.

\section{Introduction}

Building energy consumption is rapidly increased with social and economic development as well as improvement of people's living standards, thereby exacerbating reality contradictions of energy resource supply in China. Building industry is main consumer of energy. Nearly $30 \%$ energy is consumed in buildings. Building energy consumption is more than $25 \%$ of total energy consumption in China, and the growing trend is irreversible. Therefore, powerful development of building energy-saving strategy has very important significance on developing building industry from the perspectives of sustainable development strategy and 
energy development strategy. Building energy conservation has gone through three stages in developed countries: it was named as 'building energy conservation' at the beginning; the name was changed into 'energy maintenance in building' soon, namely reduction of energy dissipation in building; the action was commonly called 'improvement of energy utilization efficiency in building' in recent years, namely it does not refer to energy conservation in positive sense, but utilization efficiency improvement from positive sens $\mathrm{e}^{[1]}$. It is still called building energy conservation in China at present, its meaning should be advanced to the third level: energy should be rationally used and effectively utilized in building, and energy utilization efficiency should be continuously improved. Energy consumption is lowered, building energy conservation is implemented, it plays an important role in promoting energy resource saving and rational utilization, and easing contradiction between energy supply and economic social development in China. It also acts as an important measure for guaranteeing national resource security, protecting environment, improving people's quality of life, and implementing scientific development concept.

\section{Main Approaches of Building Energy Conservation}

Building energy conservation mainly includes two aspects: (1) Consumption restriction, namely improvement of heating (air conditioning) system efficiency and reduction of energy loss from the building itself; (2) Source expansion, namely new energy development and utilization. The following measures should be adopted from the perspective of energy conservation.

Consumption Restriction. Consumption restriction is one approach for building energy conservation, namely improvement in two aspects of improving energy system efficiency and reducing energy loss rate of building itself. Energy (energy supply) system efficiency can be improved from many aspects, such as effect of equipment itself, efficiency of transmitter, measurement of client and room temperature control measure, wherein efficiency can be improved by about $20 \%$ to $30 \%$ by client measurement and room temperature control. In addition, energy 
loss rate of building itself can be reduced, namely more and more efficient and economical heat insulation materials should be used, advanced and scientific construction technology should be reinforced to improve constant temperature effect of building and reduce energy loss rate of building itself.

Source Expansion. New energy development and utilization act as the second approach of building energy conservation, including solar energy, wind power, biomass, other new energy sources, coal natural gas and other new energies produced by technology innovation on traditional energy. Environmental pollution can be reduced to achieve sustainable development. Wherein, solar energy is the most important energy. Solar energy belongs to renewable resource, and it is urgent to renewable resources in the society with nearly exhausted non-renewable natural resources ${ }^{[2]}$. China enjoys suitable geographical location, solar energy can be well developed and utilized for supplying resources in China and meeting rapid development and people's living standard demand in China. Therefore solar energy can be utilized in buildings as much as possible for replacing other energy sources and achieving the purpose of building energy conservation.

\section{Strategy of Building Energy Conservation}

Building design adheres to the concept of energy-saving design, building energy-saving design method should be applied for designing energy-saving building, which is essential means for designer, wherein energy-saving design of building surrounding protection system, energy-saving design of external environment system and energy-saving design of building body are the most important factors for controlling building energy consumption.

\section{Energy-saving Design of Building Surrounding Protection System}

Energy-saving Design of Doors and Windows. External doors and windows are the weakest part of construction energy consumption dissipation, their energy 
consumption accounts for about two-thirds of total energy consumption in the building, including 1/3 heat loss, and 1/3 cold air infiltration. Therefore area of external window and door openings should be minimized under the condition of ensuring sunshine, lighting, ventilation and landscape requirement, air-tightness of windows should be improved, cold air infiltration should be reduced; insulation properties of the window itself should be improved, and heat transfer of window itself should be reduced ${ }^{[3]}$. (1) Room window area should be determined according to building geographical latitude, local winter sunshine rate, room lighting requirements, sunshine occlusion condition among buildings. Door and window opening area should be minimized after the above conditions are met. 2) Air-tightness of the outer doors and windows should be improved, such as setting of plastic sealing strip, use of novel door and window materials with excellent sealing performance, use of elastic and flexible light materials, elastic sealing material and sealing cream for sealing the gap between door window frames and walls, ash port can be set on edge frame, etc. Rubber, rubber or foam sealing strips, ship lap, air return duct, etc. can be used for sealing the gap between frame and sash, sealing strip, ship lap, batten outside the joint, etc. can be used for sealing the gap among sashes, and various elastic battens, etc. can be used between sashes and glass.

Energy-saving Design of Wall. Wall energy conservation is divided into heat insulation inside building and heat insulation outside the building. External wall outside heat insulation has more ideal effect compared with external wall inside heat insulation, the heating cost is greatly lowered, heat channel can be completely avoided, therefore external wall outside heat insulation is a better choice under the condition of allowable economic condition. External wall heat insulation system is more applied in actual building design application. The external wall mainly has the following structure requirements in building design. (1) Main wall structure: brickwork or concrete bearing wall thickness is determined by structure force, the surface should be smooth and firm to achieve the condition of pasting polystyrene board. When embedded iron part is reserved on the outside surface of concrete 
wall, rust-proof material should be coated. (2) Window configuration: grooves should be made on window beam of brick composite wall, thereby the polystyrene board can be affixed to the side of window, notches also should be reserved around the door and window openings of the concrete composite wall, and polystyrene board should be affixed along the notches; one heat insulation layer should be made between inside and outside windowsills under the window opening, thereby avoiding heat channel around the window openings.

Energy-saving Design of Roof. Roof accounts for lower proportion compared with external wall in the whole building surrounding protection structure area. However, it is the external surrounding wall structure accounting for the highest proportion aiming at roof rooms. If the roof heat insulation and isolation performance is worse, its influence on roof room indoor heat environment and building heating air conditioning energy consumption is more serious, therefore the following measures are adopted in the design for improving thermal performance of roof: (1) Heat insulation material with low thermal conductivity and high heat storage coefficient should be selected, meanwhile materials with high density should not be selected to prevent too high roof load. (2) There are diversified thermal insulation materials, which should be selected according to use requirements of the building, roof structure form, environmental and climatic conditions, water-proof treatment, construction conditions and other factors. Concrete material can be determined after technical and economic comparison. (3) Heat insulation layer thickness shall be determined according to thermal requirements of energy-efficient buildings, meanwhile, we also should pay attention to arrangement of material layers, thermal performance of roof is also affected by different arrangement orders, and inverted roof is advocated..

\section{Energy-saving Design of External Environment System}

Energy-saving Design of Building Greening. Temperature can be adjusted by reasonable greening, it can especially lower temperature in summer. Trees and leaves form dense shade for shielding solar radiation and reflective heat on floor, 
wall and adjacent objects. Different building greening layout methods have certain effect on energy conservation, such as street greening, greening among buildings, greening besides buildings, roof greening, wall greening, etc ${ }^{[4]}$. especially roof greening and wall greening with direct influence on indoor temperature. Tall evergreen trees and shrubs should be planted for forming sufficient greenbelt in the aspect of tree category selection, and living environment can be improved from the ecological perspective. Therefore, reasonable greening can lower operation energy consumption of building and reduce pollution as a whole during creation of healthy and comfortable living area climate.

Energy-saving Design of Shade outside Building. Shade outside the building can effectively prevent some sunshine from directly reflecting on surrounding structure of the building, which can especially prevent solar radiation from directly passing through the window and entering into the room, thereby effectively reducing indoor temperature and reaching the ultimate goal of energy conservation. External shade mode should be reasonably selected in actual design. Setting of shade outside the building is closely related to direction of building. Grid shade is a better choice for window shade, baffle shade, curtain shade, blinds shade and other modes have excellent effect on window shade. Grid shade and greening shade are more effective methods for shade of building wall and roof. Meanwhile, sunshade should be reasonably set, thereby avoiding influence on indoor air flowing speed.

Energy-saving Design of Rational Utilization of Renewable Resources. Solar energy is ecological and environmental-friendly renewable energy, necessary condition should be provided for solar energy during building design. Solar water heater is simple and effective means in residential buildings, which is widely used. Factors of combining solar energy heater with building should be fully considered during building design, placing position should be uniformly considered, and its relation with facade should be handled well. The designer should uniformly consider from the aspects of building structure as well as water supply and 
drainage. Heat collector can be perfectly combined with building on one hand, problems of preventing water, arranging pipeline, etc. also can be well solved. Solar energy technology will exert more advantages with continuous development and maturity of solar energy technology, thereby making more contribution for building energy conservation.

\section{Energy-saving Design of Building Body}

Energy-saving Design of Building Shape. Building shape and building group combination should be rationally designed during building design, thereby adapting to different climate environment ${ }^{[5]}$. Appearance of the building is simpler, the building shape coefficient is smaller, heat exchange amount is also less, and building energy-saving effect is better under general condition. If the building shape coefficient cannot meet specification requirement, the surrounding protection structure should be comprehensively judged, and thermal design standard of the surrounding protection structure can be improved.

Energy-saving Design of Building Volume. Because the relationship between the total construction area and energy conservation is shown as follows: total construction area of single building is larger, the heat transfer consumption of unit building area is smaller, factors in many aspects are integrated, total area of the building is increased, heat loss can be minimized. In addition, when the building depth is the same, but the floors are different, energy-saving effect produced due to volume increase is very prominent with increase of floor quantity aiming at single building, therefore increase of building floors also belongs to an energy-saving measure under rational condition.

Energy-saving Design of Building Direction. Direction and spacing of building have great influence on lighting and heating inside the building, therefore factors of direction and energy conservation should be considered in building layout. Buildings from north to south can avoid eastward shinning and western polarization of sun, thereby avoiding influence of solar radiation. If shade is adopted for heat insulation at the same time, the effect can be more significant. 
Therefore, after the building direction scope is determined in the design according to sunshine and sun incidence angle, the scope can be further adjusted according to monsoon dominant direction; appropriate orientation can be selected to obtain excellent cross-ventilation in summer. Building shape change of the building should be utilized maximally for utilizing more natural energy.

\section{Conclusions}

Building energy conservation is an important issue which is related to national economy as a whole, and affects long-term construction and energy safety. We must pay sufficient attention, and save massive building energy consumption in accordance with people-oriented principles and on the basis of comprehensive, coordinated and sustainable scientific development concept, thereby improving resource utilization rate, improving ecological environment, achieving harmonious coexistence between people and nature, and creating better condition for national long-term development.

\section{References}

[1]. Chuangxin Ye. Architectural Design and Building's Energy Saving, J. South Architecture.2006,12:28-29.

[2]. Xiaoying Huang. Discussion on Design and Energy-saving of Architectural, J. Industrial Buildings.2011,33(10):1-4.

[3]. Zhiye Wu. Application of building energy conservation in residential building design, J. Shanxi Architectural.2011,37(6):213-214.

[4]. Luxiu Chai, Xun Zhang, Linfei Zhang. Analysis on The Influence of Energy Save on The Development of Building Design, J. Low Temperature Architecture Technology. 2008,3:122-123.

[5]. Xiaohui Sun. Discussion about energy-saving building and building's energy saving, J. Mining Engineering.2010,3:56-57. 